\title{
LAS «CÍCLADAS» EN LA POESÍA LATINA
}

\author{
Francisca Moya del Baño \\ Universidad de Murcia \\ fmoya@um.es
}

A La Palma, la isla bonita, Llena hoy de dolor y de esperanza

\section{RESUMEN}

En estas páginas se hace un recorrido por los textos que mencionan las Cícladas en la poesía latina, mostrando la razón de su presencia en los respectivos textos y cómo las presentan los diferentes poetas.

Palabras ClaVE: Cícladas, poesía latina, comentario.

\section{THE CYCLADES IN LATIN POETRY}

\section{ABSTRACT}

In these pages a tour is made on the texts that mention the Cyclades in Latin poetry, showing the reason for their presence in the respective texts and how the different poets present them. KEYWORDS: Cyclades, Latin poetry, commentary.

0 . Es un honor poder participar en este monográfico de la revista Fortunatae. Me movió a escribir de "Cícladas» una lectura reciente de un poemario hermosísimo del poeta Carlos Clementson, pero ya me había impresionado la cultura de estas islas cuando la descubrí en las vitrinas del Museo Arqueológico de Atenas y saber que había brillado dos mil años antes de Cristo. El poemario mencionado, Archipiélagos (La Sinfonía helénica), recibió, hace ya unos años, el «Premio de Poesía José Hierro». Entre sus poemas pude gozar de la lectura de dos que llevan por título, respectivamente, "Cícladas» $\mathrm{y}$ «Espóradas». Su profunda belleza me trajo a la mente versos de algunos poetas latinos que las nombraban, impulsándome a una lectura de sus textos y a comentar lo que decían sobre estos archipiélagos. Sin embargo, me ocuparé solo de las Cícladas, ya que las Espóradas no aparecen, con este nombre, en la poesía latina. Es evidente que, si tuviésemos en cuenta cada una de las islas que forman el archipiélago ${ }^{1}$, sería imposible traer aquí todos los textos en que aparecen. Por eso, solo ofreceré los que contengan el nombre «Cícladas». Esta parada en unas islas caminando por la poesía latina, amén de su valor poético, hoy está llena, a mi juicio, de otro contenido. Ciertamente, desde hace un tiempo, y sin imaginarlo nadie, el monográfico de Fortunatae nos lleva 
y llevará siempre a pensar en La Palma, la isla bonita, una isla bella, que forma parte de un «afortunado» archipiélago. Sus islas, como las Cícladas, son hijas de un volcán; La Palma hoy sufre por ese padre, al parecer, «des-naturalizado», pero ella volverá a sonreír muy pronto y para siempre, como lo hacían las Cícladas que vio y nos hace ver Clementson. Así lo deseamos y esperamos. Comenzaré ofreciendo los versos de Clementson dedicados a este archipiélago.

1. El poema de Clementson que lleva el número 14 y el título «Cícladas» es un canto a una naturaleza en plenitud, llena de vida y alegría, una naturaleza personificada, bendita, cautivadora, que anima a la sonrisa, a la danza y, sobre todo, a lo sagrado. El poeta exhorta a contemplarlas, quiere que lo hagamos en el mejor momento, al alba; al alba, quizá, de la vida, para que así podamos gozar de su frescura y compartir, sobre todo, su danza, una danza, sin duda, sagrada.

\section{CíCLADAS}

Miradlas cómo ríen, triscan, brincan, se agrupan

Salpicando de espumas la luz fresca del alba:

Escolta fulgurante de delfines sagrados,

Síguenle al dios las islas danzando sobre el mar. (pág. 31).

El poema está lleno de movimiento, es luminoso, musical, de ritmo alegre, que, es cierto, invita a la danza. Basta reparar en los verbos («ríen», «triscan», «brincan», "se agrupan») en aposición; o en la imagen bellísima "salpicando de espuma la luz»,

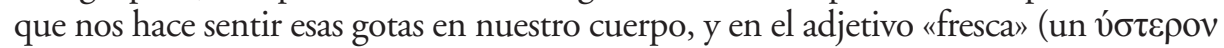

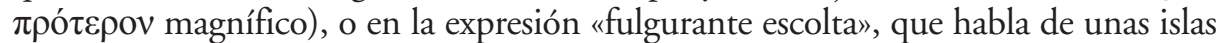
que brillan y que danzan como delfines, y, en fin, en el mar, del que surgieron y sobre el que se elevan y danzan las islas, siguiendo al dios. Clementson nos invita a la contemplación y a sentir lo sagrado, pues en Grecia, como dice el poeta en otro lugar, aunque no se crea en los dioses, se siente un cierto temblor sagrado. Y en este caso el dios al que se refiere no es otro que Apolo, el que tiene en Delos su templo. Este poema, digo, me llevó a las Cícladas².

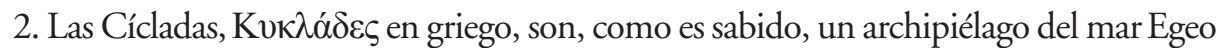
cercano a la costa del Ática y que, si escuchamos a Higino, en la fabula 276, que lleva por título Insulae maximae, constaría de nueve islas ${ }^{3}$, Andros, Miconos, Delos, Tinos,

${ }^{1}$ Lo mismo ocurre en las Cícladas y en las Espóradas, ya que muchas islas de estos archipiélagos son protagonistas en una buena cantidad de historias.

2 También el que dedica a las Espóradas, el XII: EsPÓRADAS. «Las islas... son las islas en la ilustre mañana./ La luz las ilumina, y glaucas y doradas/ Flotar parecen libres entre el azul y el cielo,/ Grandes rosas de fuego ardiendo sobre el mar». (p. 28).

${ }^{3}$ Cf. HyG. Fab. 276, 5: Cyclades insulae sunt novem, id est Andros, Myconos, Delos, Tenos, Naxos, Seriphus, Gyarus, Paros, Rhenia. (En PuIn. Nat. 4, 67, se dice Rhene). 
Naxos, Sérifos, Gíaros, Paros y Rene, aunque estas podrían ser las más importantes o conocidas, sobre todo, a juicio de Higino, pero él debía de saber que había más, que había autores que mencionaban otras islas y, además, sabían, como hoy se sabe, que había muchas; su número anda alrededor de doscientas y algunas, ciertamente, son muy pequeñas. El nombre del archipiélago está relacionado, como es sabido, con $\kappa \cup ́ \kappa \lambda o s$, 'círculo', porque, como es opinión predominante ${ }^{4}$, el conjunto de las mismas forman la figura geométrica de un círculo, en el centro del cual se yergue la isla de Delos, siendo Apolo el que, desde el templo que tiene en esta isla, ostenta el dominio de la misma y, a su vez, recibe la veneración de las islas que a su alrededor parecen dirigir a Delos su mirada. No obstante, hay que recordar que hay otra explicación del nombre de Cícladas; es la de Servius 5 , según el cual, su relación con "círculo» ( $\kappa \cup ́ \kappa \lambda \circ \varsigma)$ no indicaría que las islas formen esta figura, sino el rodeo que hay que dar a las islas para evitar navegar por en medio de ellas, interpretación que también parece verosímil y complementaria, porque, como dejan claro igualmente nuestros textos, es peligroso atravesar las Cícladas, sobre todo, en tiempo de tormentas, y las evitarían. Por fin, tras este breve y, sin duda, innecesario recordatorio, vamos ya a los textos poéticos que en la literatura latina mencionan las Cícladas.

\section{CATULO}

La primera aparición de las Cícladas se encuentra en el poema cuarto de Catulo, dedicado a un phasellus. Este, al haberle dado la palabra el poeta, dice que él aventajó en rapidez a las naves (Phasellus ille quem videtis, hospites/ ait fuisse navium celerrimus, vv. 1-2), afirmando que tiene testigos que lo corroboran, entre ellos, las islas Cícladas.

Et hoc negat minacis Adriatici negare litus insulasve Cycladas

Rhodumque nobilem horridamque Thraciam,

Propontida trucemve Ponticum sinum7. (CATVLl. 4, 6-9).

${ }^{4}$ Estrabón, Plinio, Solino, Amiano Marcelino hablan de la redondez del conjunto, o de que las islas están alrededor de la de Delos. Cf. La Cerda (1612: 300), que en su comentario a sparsas per aequor Cycladas (Verg. Aen. 3, 126 ss.) ofrece, como suele, clara y amplia información.

${ }^{5}$ Así leemos en Servius (1961: I, 366): Cyclades vero non ideo dicuntur, quia in rotunditate sunt, sed quod longo ordine eas circumire necesse est.

${ }^{6}$ "Aquella barquilla que veis, viajeros, dice que fue la más rápida de las naves». Hospites puede entenderse como amigos a los que hospeda Catulo en su casa y ahora caminan por el puerto. Añadiré una traducción literal a todos los textos.

${ }^{7}$ «Y esto dice que no lo niegan la costa del amenazador Adriático, ni las Cícladas y la célebre Rodas y la hórrida Propóntida tracia [mar de Mármara], ni el fiero golfo Póntico». 
Los otros testigos eran, lógicamente, los que también contemplaron el itinerario, posiblemente de Catulo, en su viaje de regreso de Bitinia. ${ }^{8}$. El phasellus se construiría en el punto de partida, como el poeta indica (vv. 11-18). De regreso, el mar Adriático sería el último mar que navegase; en cambio lo sitúa en primer lugar. El poeta mencionaría el viaje desde el «aquí» y el «ahora». Catulo ordena el viaje de modo invertido, desde la llegada a la salida. Nada se dice en especial de las Cícladas; su presencia informa que de que están en el camino de la barquilla y evocan el mar Egeo, pero es importante que estén mencionadas y que Catulo, poéticamente, las personifique, como a los demás elementos, ya que dan fe de que el phasellus era muy rápido. Su presencia es sencilla pero importante.

\section{VIRGILIO}

4.1. En Virgilio encontramos las Cícladas en el viaje que Eneas y los suyos hicieron para llegar desde la isla de Ortigia (el nombre antiguo de la isla Delos) a la de Creta, isla esta que creían que era el lugar de su destino. Es Eneas el que refiere que, tras decidir marchar a Creta, salieron del lugar y recorrieron las islas. La voz del poeta ofrecerá notas interesantes de las islas por las que pasan. Se trata de un bello y poético texto, el primero que en la poesía latina se dedica a las Cícladas.

Ellos, dice, pasaron por Naxos, Donusa', Oléaros, Paros y, tras mencionar estas, añade las Cícladas. Parece que están aquí indicando que pasaron por otras Cícladas. Menciona solo cuatro islas - una con un nombre distinto (Ortigia) al que aparecía en el texto de Higino (Delos), y otra (Oléaros), ausente de la relación del mitógrafo-. A Cícladas añade un adjetivo, sparsae, las islas están 'esparcidas'.

linquimus Ortygiae portus pelagoque volamus

bacchatamque iugis Naxon viridemque Donusam,

Olearon niveamque Paron sparsasque per aequor

Cycladas, et crebris legimus freta concita terris ${ }^{10}$. (VerG. Aen. 3, 124-127).

En el primer hexámetro de este pasaje encontramos dos verbos destacados en posición inicial y final, respectivamente: linquimus y volamus, se siente el movimiento que su significado comunica, la hipérbole de «volar» lleva a pensar en las aves

${ }^{8}$ Cf. Pérez Vega - Ramírez de Verger (2005: 470 ss.)

${ }^{9}$ En el nombre de esta isla hay variantes en latín (Donusa, Donysa). Siempre traducimos por Donusa.

${ }^{10}$ «Abandonamos el puerto de Ortigia y a través del piélago volamos, y bordeamos Naxos, que hizo retumbar por los montes el nombre de Baco, la verde Donusa, Oléaros y la nívea Paros y las Cícladas esparcidas por la llanura marina, y surcamos los estrechos agitados por las abundantes tierras». 
y esa imagen se traslada a las naves. Ayuda a sentir esa rapidez el predominio de dáctilos que hay en el hexámetro. Así representa el poeta la marcha del puerto de Ortigia ${ }^{11}$, en el que estaban protegidas las naves. Y merece la pena reparar en portus (portus en plural poético). El puerto de Ortigia-Delos no era muy grande ni importante. Sí tenía, sin embargo, dos puertos la Ortigia de Siracusa, en la isla de Sicilia. Virgilio pudo pensar en ella o atribuir a la cíclada del Egeo los puertos que tenía la siciliana. Evocada, ciertamente, lo estaba.

Después de Ortigia nombrará el poeta a otras cícladas, que se encuentran en el camino a Creta. Tras los dos verbos del primer verso del pasaje hay que esperar tres versos para encontrar el tercero, coordinado con los anteriores: legimus, este indica que van marchando, rozando las islas que Virgilio va adornando con sus adjetivos. En cuanto a la elección del adjetivo, participio, bacchata, Virgilio sabía de cuántas maneras podía interpretarse; la plurisignificación enriquece el pasaje; es evidente que Naxos es isla en la que Baco tiene su presencia, su morada; allí encontró a Ariadna abandonada cuando regresaba de la India con su cortejo de bacantes; con ella se casaría. En Naxos, también llamada Día, danzaban las bacantes en los montes, aclamaban a gritos al dios con su grito ritual (euhan, euohe, euhium), llenas, como es lógico, del «líquido divino». Todo esto y más evoca bacchata; también podría aludir, como es lógico, a que la isla estaba cubierta, sobre todo, en las laderas de sus montes, de las vides de Baco. También el nombre de la isla se relaciona, por otra parte, con Dioniso-Baco, como indica el verbo vágal, que se corresponde con bacchari. El adjetivo que elige Virgilio es muy elocuente.

Al mencionar a la isla de nombre Donusa dice que es «verde»; podría serlo por verdear debido a la abundancia de hiedra dedicada a Dioniso (Dioniso podría estar, como se ha indicado, también detrás de su nombre), pero igualmente podía ser dicha «verde» por su mármol, distinto, lógicamente, del mármol blanco de Paros (cf. niveam).

En cuanto al conjunto de las Cícladas, Virgilio les atribuye su condición de sparsae, esparcidas, derramadas, como si hubieran sido sembradas por la llanura marina (per aequor), una siembra que se aviene a la forma de círculo de islas alrededor de Delos ${ }^{12}$. Al final, tras mencionar las islas y cerrar la relación con Cycladas, Virgilio quiere aludir a lo peligroso que era navegar por las Cícladas, en especial, cuando el mar no estaba en calma, debido a las tormentas que sufría este lugar por el viento, y habla de freta. Freta ('aguas', espacios estrechos del mar que hay entre las islas, es término que se emparienta con fervere, 'arder', 'hervir') y legimus (aquí, 'surcamos', acudiendo

${ }^{11}$ Es sabido que se dice que esta isla errante se llamó antes Ortigia. En ella nacieron Ártemis y Apolo y, después de nacer Apolo, se llamó Delos, pero también algunos dicen que Ártemis nació en Ortigia y Apolo ya en Delos. Cf. Ruiz de Elvira (1975: 78).

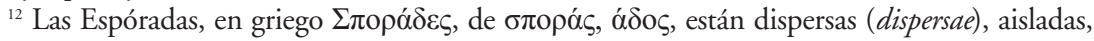
aunque también puedan parecer sembradas, sparsae. Pero no formando un círculo. 
a un zeugma) indican que las naves surcaron esos estrechos concita ('agitados', 'removidos'); el adjetivo verbal concita apoya la idea de «hervir el agua» que sugería freta, indicando también el movimiento singular, arremolinado, de estas aguas por causa de las tierras abundantes (crebris terris), es decir, por las islas y, sobre todo, islotes y escollos, que favorecen esa agitación del mar por el choque de las olas con las muchas y escarpadas orillas. Eso es, si se acepta, como preferimos, concita $^{13}$, en vez de consita. Virgilio, ciertamente, ha dado a las Cícladas una presencia en su Eneida que ha servido de ejemplo a los poetas que lo admiraban e imitaban.

4.2. En el libro octavo volverá a mencionarlas. En esta ocasión le proporcionan un bello y muy adecuado símil. En Accio todo está previsto. Virgilio presenta, como si de un escenario teatral se tratara, a los personajes del drama que se iban a poner en movimiento. Vemos que ya todos corrían a la vez y espumaba todo el mar sacudido por los remos de las naves. Se dirigen a alta mar. El poeta los contempla y le vienen a la mente las Cícladas, y las ve nadando en el agua, como ahora las naves enemigas; también estas, dirá, se asemejan a elevados montes que chocan contra otros montes.

Una omnes ruere ac totum spumare reductis convulsum remis rostrisque tridentibus aequor. 690 alta petunt; pelago credas innare revolsas ${ }^{14}$ Cycladas aut montis concurrere montibus altos, tanta mole viri turriti puppibus instant ${ }^{15}$. (VerG. Aen. 8, 689-693).

Virgilio en los dos primeros hexámetros acude a dos infinitivos descriptivos (ruere y spumare), llenos de movimientos («irrumpían» todos a una; toda la llanura marina "espumaba»). Hay, ciertamente, un enorme y buscado desequilibrio entre las dos oraciones a favor de la segunda; el poeta se centra en el mar y a él dirige nuestra mirada. Lo consigue situando a bastante distancia, y en primer y último lugar de la frase, totum y aequor, que van juntos, y añadiendo a aequor el participio convulsum en lugar destacado en el verso, y, en medio, como abrazado, de reductis remis.

${ }^{13}$ Aunque consita también es lectura de algunos manuscritos y algunos la defienden, preferimos la lectura concita, siguiendo, sobre todo, el comentario de La Cerda, que ofrece en su apoyo un texto de Paulino, ep. 34 (Siciliam transcurrit, circa quam concita et vorticosa crebris, ut ferunt, insulis freta). Cf. La Cerda (1612: 297 y 300). de preferir.

${ }^{14}$ Prefiero la forma arcaica, en vez de revulsas, porque, a mi juicio, también Virgilio la debió

${ }^{15}$ «A la vez todos se precipitaban, y se llenaba de espuma la llanura entera perturbada por los remos y los espolones de tres puntas. Se dirigen al mar profundo; creerías que nadaban en el piélago, arrancadas de sus cimientos, o que montes elevados chocaban con montes. Con naves provistas de torres de tan gran volumen atacan los hombres». 
Merece la pena reparar en el también descriptivo reductis, que hace casi visible el movimiento de los remos empujados por la fuerza de los brazos; la sucesión de la «r» en el verso nos hace casi escuchar ese movimiento, e, incluso, el de los espolones de tres puntas (cf. rostris tridentibus) que se añaden a los remos. El lector puede ser espectador de lo que ocurre.

En los versos 691ss., en que aparecen las Cícladas, la disimetría es semejante. Alta petunt recuerda al anterior Vna omnes ruere. Ahora solo dos palabras. A continuación, Virgilio con no muchas, pero sí bastantes, más palabras, distribuidas en dos hexámetros nos hace ver (él solo dice "creerías» - credas-, pero ha bastado) a las Cícladas nadando, como las verá danzar Clementson. Las miradas eran distintas; la realidad, también. En este caso revolsas deja claro que la violencia que se respira en las naves es similar a la violencia de la naturaleza que ha sido capaz de arrancar del fondo marino a las islas. Virgilio ha elegido deliberadamente el participio revolsas, de la misma familia del anterior convulsum; ambos términos ocupan posiciones destacadas, uno, el principio y otro, el final de verso, respectivamente. Esa es la situación que se vive. Añadir la imagen de montes chocando con montes evoca los imaginados choques producidos por el viento de unas cícladas contra otras, que, por el poder de la Naturaleza, han dejado de estar fijas para andar errantes, pero también evoca que esa sensación era la de los marineros que se encontraban en esa parte del Egeo, cuando sufrían una peligrosa tempestad. Ahora, en Accio, es igual. Virgilio, como ya hemos recordado, dio protagonismo a estas islas y las embelleció con sus versos, y les abrió la puerta para entrar por ella en la poesía latina. Lo iremos viendo.

\section{HORACIO}

5.1. En dos ocasiones encontramos en Horacio las Cícladas. La primera vez, en la oda 14 del libro primero ${ }^{16}$, escrita en estrofa asclepiadea ${ }^{17}$, que dedica, lleno de temor, a una nave, y que así comienza: $O$ navis, referent in mare te novil fluctus. O quid agis? ${ }^{18}$. Horacio no ve con buenos ojos que la nave marche hacia Oriente; no está en condiciones de soportar los peligros de una navegación como la que pretende; pero, consciente de que no va a obedecerlo, le dice que debe llevar cuidado; el último consejo que le da es que evite las Cícladas, es decir, atravesar el mar Egeo por en medio ellas. Así cierra la oda Horacio.

${ }^{16}$ Sobre esta oda se ha escrito mucho desde Quintiliano $(8,6,44)$, pero no es de este momento ni siquiera recordarlo. Es bien sabido.

${ }^{17}$ De dos asclepeiadeos menores, de doce sílabas, un ferecracio de siete y un gliconio de ocho.

${ }^{18}$ «Oh nave, te llevarán al mar nuevas olas! ¡¿Oh, qué haces?!». 
Nuper sollicitum quae mihi taedium,

nunc desiderium curaque non levis,

interfusa nitentis

Vites aequora Cycladas ${ }^{19}$. (Hor. Carm. 1, 14, 17-20).

Horacio sitúa en lugar final, en el último gliconio ${ }^{20}$, el nombre del archipiélago, tras haber destacado su brillo en la posición final del verso que le precede (nitentis). Lo que debe evitar es, lógicamente, el mar, aquí en plural (aequora), en vez de aequor, que recuerda el freta de Virgilio en vez de fretum. Es claro que lo que se quiere destacar en ambos casos son esos «espacios marinos» que se encuentran entre las islas; por eso es muy ilustrativo el adjetivo verbal inter-fusa; se trata del agua, es decir, de las «diferentes» aguas, según las islas o islotes entre los que se encuentra. Merece la pena insistir en el adjetivo nitentis, acusativo arcaico, con el que aplica a las Cícladas el brillo que deriva del mármol que hay en algunas de ellas (en Virgilio la «nívea» Paros, la «verde» Donusa). Y, en cuanto al orden de palabras, es muy propio de la poesía, ya que sitúa al final el acusativo Cycladas, que complementa al participio interfusa, que aparece en primera posición. En fin, Horacio, como Virgilio, pone en su obra las Cícladas; sabe que son peligrosas para la navegación; entre ellas están los aequora interfusa, como los freta en Virgilio. Destaca su brillo (nitentis); en Virgilio, el color de algunas (nivea, viridis).

5.2. En la oda 3.28 Horacio desea celebrar las fiestas de Neptuno con un buen vino y quiere dirigir su canto (lo hace en dímetros de asclepiadeos menores y gliconios), a los dioses, e invita a Lide a que lo acompañe. Cantarán los dos a Neptuno y las Nereidas; Lide será la que cante a Latona y a la Cintia, es decir, a la madre y hermana de Apolo, y dedicará el último canto a Venus; la diosa no es nombrada, pero sí ofrece Horacio los datos necesarios para ser identificada. Entre ellos se encuentran las Cícladas.

summo carmine, quae Cnidon

fulgentisque tenet Cycladas et Paphum

iunctis visit oloribus

dicetur $^{21}$. (Hor. Carm. 3, 28, 13-16).

Horacio menciona Cnido y Pafos, dos islas no pertenecientes al archipiélago de las Cícladas, en las que la diosa del amor, Afrodita-Venus tenía un templo, como

\footnotetext{
${ }_{19}$ «Tú (sc. nave), que hace poco eras para mí tedio, y ahora deseo y no leve cuidado (objeto de su cuidado y amor), evita el mar que se extiende entre las brillantes Cícladas».

${ }^{20}$ Está escrita en la estrofa asclepiadea de dos endecasílabos asclepiadeos, un ferecracio y un gliconio.

${ }^{21}$ «En el último canto será nombrada la que posee Cnido y las fulgentes Cícladas, y con sus cisnes uncidos visita Pafos».
} 
bien se sabe. Había, ciertamente, templos o altares dedicados a la diosa en muchas ciudades $^{22}$. En cuanto a las Cícladas, que sitúa en medio de las dos islas, Horacio pudo pensar en Thera, hoy Santorini, isla que tuvo un templo dedicado a esta diosa o, como sugiere el plural, en otras que también tendrían templo o altar dedicado a ella. Como tenet indica, Afrodita-Venus era la señora de estas islas; los dioses visitaban sus "posesiones» y esta visita sus templos (visit) en su carro tirado por cisnes (cf. oloribus). Es evidente que se trata de ella. En cuanto a cómo ve aquí Horacio las Cícladas, lo dice fulgentes (en el texto anterior leíamos nitentes).

\section{OVIDIO}

6.1. Con Ovidio volvemos de nuevo a un viaje, en este caso el de la imagen de Cibeles, la Madre de los dioses, que desde Frigia fue conducida a Roma. Ovidio en Fastos lo narra ampliamente (Ov. Fast. 4, 179-372), al cantar la historia de la fiesta de esta diosa que se celebraba el 4 de abril. Narrará la ruta de la nave que transportaba a la diosa desde su salida hasta llegar a la tierra Ausonia, en concreto, a Ostia, lugar por el que el Tíber desemboca en el mar (vv. 277-294)23. En ese viaje la diosa -y la nave en la que viaja- son acogidos (excipiunt) por las Cícladas, después de haber dejado atrás otras islas, Lesbos y Eubea (Cáristos es una ciudad de Eubea).

Cyclades excipiunt, Lesbo post terga relicta, quaeque Carysteis frangitur unda vadis ${ }^{24}$. (Ov. Fast. 4, 281-282).

Nada en este dístico elegíaco dice Ovidio de las Cícladas, salvo que el verbo elegido, excipiunt, sugiere la hospitalidad de unas islas que acogen a la diosa en su ruta. El mar y los vientos fueron propicios. No hay que olvidar que, como dice Ovidio al principio del pasaje, la diosa iba segura por el reino de su hijo, Posidón-Neptuno, aunque no se menciona el nombre (illa sui per aquas fertur tutissima nati, v. 277). Ninguna tempestad podía hacer daño a la nave que conducía a Cibeles, la diosa Madre. Las Cícladas también se beneficiaron de este viaje de Cibeles.

6.2. Las Cícladas aparecen en el mismo libro cuarto en otro viaje, en esta ocasión, el de Ceres. El día 12 de abril se celebraban en Roma los Juegos en honor

${ }^{22}$ El comediógrafo del siglo IV a. C. Philataerus ironiza: «en todas partes hay templos de Afrodita la amante, y en ninguno altares de Afrodita, la diosa casada». Tomo el dato de https://es.wikipedia.org/wiki/Afrodita\#Templos (9 de octubre de 2021).

${ }^{23}$ Ovidio continuará con el conocido «milagro» que tuvo lugar tras encallar la nave.

${ }^{24}$ «Las Cícladas la acogen, dejada Lesbos a la espalda y el agua que se rompe en los vados de Cáristos». 
de esta diosa. Ceres fue la que regaló a los hombres el don de la agricultura, en concreto, a Triptólemo. Lo comunica en casa de Celeo, su padre. La diosa había sido acogida por Celeo y su hija, cuando la vieron sentada en una piedra con el aspecto de una pobre anciana. De la casa salió, tras intentar hacer inmortal a Triptólemo, para seguir buscando, en su carro alado, a su hija Prosérpina. Como estaba en Eleusis (lo que sería Eleusis), comenzó su viaje desde allí y, dejando atrás el cabo de Sunio y el puerto del Pireo, llegaría al lugar del Egeo en que estaban las Cícladas; después, al mar Jónico y al de Ícaro, etc. No dejó región alguna del mundo que no visitara. Decía así Ovidio:

Sunion expositum Piraeaque tuta recessu

linquit et in dextrum quae iacet ora latus;

hinc init Aegaeum, quo Cycladas aspicit omnes,

Ioniumque rapax Icariumque legit ${ }^{25}$. (Ov. Fast. 4, 563-566).

Ovidio se limita a su mención; era obligado y, como es natural, lo hace al principio, ya que las Cícladas están situadas en la costa del Ática, y la diosa había permanecido muy cerca de Atenas. No omite que están situadas en el mar Egeo y sugiere que son muchas, puesto que informa de que la diosa vio todas las islas (Cycladas omnes).

6.3. También en Metamorfosis menciona Ovidio las Cícladas. En el libro segundo, al narrar el mito de Faetón, cuando da cuenta de los males que ha producido en el mundo que sea él quien conduzca el carro, señalará el resquebrajamiento del suelo que permite que la luz llegue al Tártaro, el encogimiento del mar que convierte en arenal el océano y deja a la vista los montes que hay debajo del mar, y, finalmente, el aumento del número de las Cícladas:

dissilit omne solum, penetratque in Tartara rimis

lumen et infernum terret cum coniuge regem;

et mare contrahitur siccaeque est campus harenae, quod modo pontus erat, quosque altum texerat aequor, exsistunt montes et sparsas Cycladas augent ${ }^{26}$. (Ov. Met. 2, 260-264).

De las Cícladas Ovidio en este texto solo menciona que están sparsae, como decía Virgilio, y que aumenta el número de ellas; se sobreentiende que son muchas.

${ }_{25}$ «Deja en la retirada el accesible Sunio y el seguro Pireo y la ribera que yace al lado derecho; de aquí entra en el Egeo, en el que ve todas las Cícladas, y recorre el voraz Jonio y el mar Icario».

${ }^{26}$ "Todo el suelo se resquebraja, y penetra en el Tártaro por las rendijas la luz, y aterroriza al dios del infierno con su cónyuge; el mar se contrae, y es un campo de seca arena lo que hace poco era océano, y emergen los montes a los que la llanura profunda había cubierto y ellos aumentan las esparcidas Cícladas». 
6.4. De nuevo Ovidio menciona a las Cícladas, de nuevo se trata de un viaje, pero en este caso es el suyo. Da cuenta de él en la elegía 11 del libro primero de Tristia, la cual sirve de epílogo al libro. El viaje, pues, es el que le llevó a su exilio (de fuga habla Ovidio: nostrae fugae, v. 6). En este poema en dísticos elegíacos también Ovidio informará al lector de que los poemas que componen este libro han sido escritos todos durante este viaje (Littera quaecumque est toto tibi lecta libello, / est mihi sollicito tempore facta viae $e^{27}$, vv. 1 ss.), ya, dirá, en medio del mar Adriático, o después, y en otra nave, tras haber superado el Istmo de Corinto, en medio del Egeo, como la mención de las Cícladas indica. Estas Cícladas de Ovidio muestran ciertas diferencias con las que nos han ofrecido, por lo general, los textos anteriores. Estas Cícladas parece que son capaces de senti ${ }^{28}$, de «asombrarse». Merece la pena, por tanto, destacar cómo Ovidio las humaniza o cómo el sufrimiento del ser humano puede mover y hasta conmover a la naturaleza.

aut haec me, gelido tremerem cum mense Decembri, scribentem mediis Hadria vidit aquis;

aut, postquam bimarem cursu superavimus Isthmon,

alteraque est nostrae sumpta carina fugae,

quod facerem versus inter fera murmura ponti,

Cycladas Aegaeas obstipuisse puto ${ }^{29}$. (Ov. Trist. I, 11, 3-8).

Ovidio ha escrito sus poemas en medio de las aguas, en el Adriático, primero, en el Egeo, después; estos mares los vieron, pero no lo expresa igual. Tras decir que o el Adriático me vio (aut vidit) escribiendo en el mes de diciembre en medio de sus aguas, no continúa con otro aut vidit para referir que también lo vio el Egeo o lo vieron (aut viderunt) las Cícladas, sino que la disyuntiva aut no relaciona dos verbos iguales, porque ha preferido pasar a la primera persona (puto). La disyunción se establece entre aut vidit, aut puto. Ovidio necesita la primera persona para mostrar sus pensamientos; no puede afirmar lo que quería decir, aunque lo cree. Ovidio piensa que las Cícladas, al verlo y ver lo que hacía, se asombraron (obstipuisse), concretamente, de que compusiese versos (facerem versus) en las condiciones en que estaba el mar (inter fera murmura ponti). El arte ovidiana ha situado el verbo puto a bastante distancia de vidit, y el significado de este verbo permanece en el aire y esta acción de «ver» está implícita -es la causa- en el asombro de las Cícladas. Ovidio no dice que se

\footnotetext{
de mi camino".

${ }^{27}$ «Cualquier letra que tú has leído en este librito la he escrito yo durante el agitado tiempo

${ }^{28}$ En el poema de Catulo, el poeta les atribuía la voz.

${ }^{29}$ "O a mí el Adriático me vio escribiendo estas cosas en medio de sus aguas temblando de frío en el mes de diciembre, o, después de haber superado en nuestro camino el Istmo de Corinto (entre dos mares) y después de que se tomó para nuestra fuga la segunda nave, pienso que las Cícladas egeas se asombraron de que yo compusiera versos entre los fieros bramidos del ponto».
} 
asombraron, pero él sí pudo pensar que lo hicieron, porque sabía, como vates que era, que podían reaccionar como seres vivos. Así las ve el poeta. No dice más de ellas, salvo que están en el Egeo, pero lo que dice con obstipuisse es mucho y está lleno de profunda poesía.

\section{MANILIO}

Al hablar del mundo conocido, el poeta lo hará también del mar Mediterráneo, de los nombres diferentes que posee según los lugares y mencionará luego las islas que en él se encuentran (cf. MANIL. 4, 628-641). Así, las grandes, como Cerdeña, Sicilia, Eubea, Creta, Chipre, y también otras que así mismo emergen de un único y pequeño mar, como las Cícladas. De ellas menciona Delos (Cícladas y Delos), añadiendo en el mismo hexámetro Rodas y continúa con otras islas (Áulide, Ténedos, Córcega, Ibiza y las Baleares).

$<$ has praeter terras, celebrat quas maxima fama, $>$

$635^{a}$ totque minore solo tamen emergentia ponto litora, inaequalis Cycladas Delonque Rhodonque Aulidaque et Tenedon vicinaque Corsica terris litora Sardiniae primumque intrantis in orbem Oceani victricem Ebusum et Balearica rura, innumeri surgunt scopuli montesque per altum ${ }^{30}$. (MANIL. 4, 635a-641).

Manilio menciona las Cícladas; tenía que mencionarlas, como unas más de las muchas islas que se encuentran en esta parte del Mediterráneo, el mar Egeo. El adjetivo que las acompaña, inaequales, informa de algo evidente: las Cícladas son diferentes unas de otras. Luego, Manilio seguirá «su ruta» y llegará a otra parte de Mediterráneo, y, hablando de islas, una buena lista de ellas encontramos en estos hexámetros.

\section{CIRIS}

En el poema, epilio, que lleva el título de Ciris, atribuido desde la antigüedad, como se sabe, a Virgilio ${ }^{31}$, se narra la metamorfosis de Escila, hija del rey de Mégara

\footnotetext{
${ }^{30}$ «Además de estas tierras, que celebra la máxima fama, y de tantos litorales que, sin embargo, emergen en uno solo y menor ponto: las desiguales Cícladas y Delos y Rodas, y Áulide, y Ténedos, los litorales corsos vecinos a las tierras de Cerdeña, y, vencedora del Océano que entre en la primera tierra, Ibiza, y los campos baleáricos -además-, emergen por alta mar innumerables escollos y montes».

${ }^{31}$ Se sigue discutiendo sobre esta autoría. También Ausonio ha sido señalado como autor. A nuestro juicio no sería del todo indigno de Virgilio, sobre todo, de un Virgilio joven poeta. Cf. Moya del Baño (1982: 438-446).
} 
la cual, enamorada de Minos, que asediaba el reino de su padre, le cortó a este el mechón de pelo que era el garante de su vida y de su reino. Minos, contra lo que la joven esperaba y deseaba, no se casó con Escila para premiar su traición, sino que, después de haber tomado la ciudad de Mégara, regresó a Creta, con la joven atada a su nave. En este viaje, como dice el «narrador», iba a contemplar Escila, entre otros lugares, las Cícladas. Fue lo último que vio antes de ser transformada en ciris o garceta, el ave marina con la que suele identificarse. Así leemos:

iamque adeo tutum longe Piraeea cernit et notas, eheu frustra, respectat Athenas. Iam procul e fluctu Salaminia respicit arva

florentisque videt iam Cycladas: hinc venus ${ }^{32}$ illi

Sunius, hinc statio contra patet Hermionaea.

linquitur ante alias longe gratissima Delos

Nereidum matri et Neptuno Aegaeo;

prospicit incinctam spumanti litore Cythnom

marmoreamque Paron viridemque adlapsa Donysam

Aeginamque simul salutiferamque Seriphum ${ }^{33}$. (CIRIS 468-477).

En estos hexámetros el autor del epilio cierra el viaje de Escila nombrando y deteniéndose en algunas Cícladas, de las que da algunos detalles; se percibe un interés por describir lo que Escila está viendo y, sin duda,valorando, puesto que todo lo ha perdido con su impiedad. Las Cícladas son calificadas de florentes, en el sentido de 'brillantes', pensando, sin duda, en los mármoles de Paros o los de Donusa; la idea de brillo es habitual y está en Horacio, al calificarlas de nitentes y fulgentes. Cuando habla de Delos, nada dice el autor de Apolo ni tampoco de su hermana, sino que se centra en la relación que tiene la isla con las divinidades del mar, con Doris, la madre de las Nereidas (el padre era Nereo), y con Neptuno-Posidón. Es para ellos la isla preferida ${ }^{34}$. Añade otra cíclada, Citno ${ }^{35}$, destacando en ella la espuma que la rodea, cuando el mar está embravecido. A Paros la califica de mamorea, y de Donusa dice que es verde, como hacía Virgilio, pudiendo serlo, como se ha recordado, por el mármol

${ }^{32}$ Venus es la lectio de los manuscritos, que ha sido sustituida por diversas conjeturas, entre las que predomina sinus, genus, vetus.

${ }_{33}^{33}$ «Luego distingue a lo lejos el seguro Pireo, y contempla, jay! en vano, la conocida Atenas. Ya a lo lejos, desde el mar, ve los campos de Salamina y ve después las brillantes Cícladas. Aquí, frente a ella, está la belleza, Sunio y allí, enfrente, el puerto de Hermione. Es abandonada Delos, entre otras, la más grata con mucho para la madre de las Nereidas y para Neptuno, el señor del Egeo. Divisa ante sí Citno, rodeada de espumante litoral, y la marmórea Paros; y, deslizándose junto a ella, la verde Donusa y, a la vez, Egina y la saludable Sérifos».

${ }^{34}$ Estacio dice que Delos es la morada tranquila de las Nereidas (STAT. Ach. 1, 391).

${ }^{35}$ Es una pequeña isla, perteneciente a las Cícladas occidentales, que se encuentra entre Ceos y Sérifos. 
de ese color o por las hiedras. Nada añade al nombre de Egina y, por fin, de salutífera o saludable califica a Sérifos, aquella isla pequeña a la que enviaban a algunos condenados los romanos ${ }^{36}$. A continuación la joven será metamorfoseada en ave marina, que, como tal, podrá seguir viendo desde el cielo las Cícladas. Antes las veía desde el agua (e fluctu, v. 470).

\section{SÉNECA}

9.1. Séneca en su Agamenón hablará de una Cíclada, Lesbos; la menciona al dirigir el Coro sus oraciones a la diosa Ártemis. Esta se incluye en un amplio canto que anima a todos a dar gracias a los dioses, comenzando por Apolo, porque el rey Agamenón había vuelto victorioso de la guerra de Troya. Después de Apolo, encontramos a Juno, Palas; luego a Ártemis y, finalmente, a Zeus (cf. SEN. Ag. 310-407). Nada sabía el Coro de que se preparaba la muerte de Agamenón y de que pronto será asesinado. Los versos que dirigen a Ártemis, en los que se encuentra la mención de la Cíclada, comienzan así:

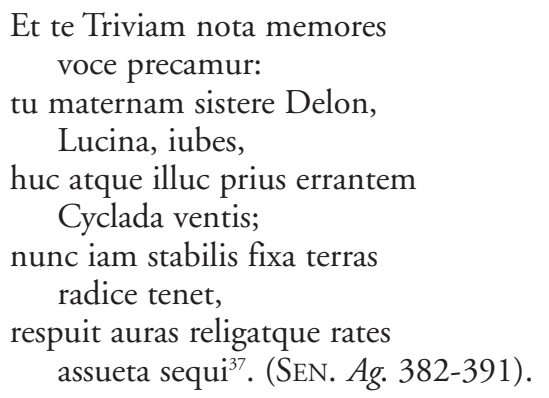

Como todo el canto, estos versos también son dímetros y monómetros anapésticos. En ellos Séneca acude al mito; se refiere a Ártemis como Trivia, la diosa de las encrucijadas $^{38}$ y como Lucina, la de los alumbramientos; por haber nacido la primera, después, como partera, ayudó a su madre a dar la luz a Apolo; y le atribuye a ella que la isla dejase de vagar ${ }^{39}$. Latona, su madre, es bien sabido, no podía dar a luz en tierra firme, porque Juno lo había prohibido; por eso, la pudo acoger la Cíclada

${ }^{36}$ Cf. infra en el texto de Juvenal.

${ }^{37}$ «Y a ti, Trivia, te imploramos agradecidos con voz que conoces. Tú, Lucina, mandas detenerse a la materna Delos, antes una Cíclada que vagaba por acá o por allá, según los vientos. Ahora ya con su raíz fijada tiene firme su tierra, rechaza los aires y, acostumbrada a seguirlas, amarra las naves».

${ }^{38}$ También se entiende como la diosa Ártemis en la tierra, Luna en el cielo y Hécate en el infierno.

${ }^{39}$ Hay variantes en el mito. Cf. Ruiz de Elvira (1975: 75-77). 
errante. Séneca se ha detenido en mostrar el antes y el ahora de una isla protegida por la divinidad. Ahora está fijada a sus cimientos, su tierra es estable; en ella, además, confían las naves que descansan seguras amarradas a ella, recordando que antes la isla caminaba detrás de las mismas. Es un hermoso canto a la más importante isla de las Cícladas, y como todo lo que dice el Coro, tan hermoso y confiado, contrasta con el horror que va a vivir con el asesinato de Agamenón.

9.2. En Thyestes también menciona Séneca a las Cícladas. El coro se siente feliz de que hayan hecho los hermanos Atreo y Tiestes las paces, y entona un bello canto de alabanza al amor, sobre todo, al amor de la familia, pues hace posible superar los enfrentamientos, y lograr la calma y la paz. Para dejarlo claro con un ejemplo, acude al símil del mar embravecido por los vientos que se convierte en un mar tranquilo, lleno de velas, que acoge a una pequeña barquilla y en el que se puede contemplar el fondo y contar los peces, lógicamente, una vez que aquellos enfrentamientos han cesado. Entre los muchos ejemplos que ofrece Séneca está el de las tempestades de las Cícladas.

alta, quae navis timuit secare,

hinc et hinc fusis speciosa velis

strata ludenti patuere cumbae,

et vacat mersos numerare pisces

hic ubi ingenti modo sub procella

Cyclades pontum timuere motae ${ }^{40}$. (SEN. Thy. 590-595).

El nombre de las Cícladas en esta tragedia muestra una de las características de este archipiélago, como bien sabía Séneca. Son frecuentes y peligrosas las tempestades; lo indica sub procella. También aquí las Cícladas son capaces de sentir, en este caso 'sentir miedo', 'temer' (timuere), cuando están o han sido motae, participio que puede entenderse como 'conmovidas', pero también, 'agitadas' (cf. concita en Virgilio), como las aguas, o, incluso, 'errantes', por verse o sentirse «separadas» de sus cimientos. Ese clima de miedo aparece al principio del pasaje (navis timuit), pero la nave dejó de temer, cuando reinó la calma, y en la calma se recuerda que antes las Cícladas temieron.

\section{SILIO ITÁLICO}

En Silio Itálico encontramos las Cícladas formando parte de un símil utilizado por el poeta para expresar el efecto que provoca la figura de Aníbal marchando

${ }^{40}$ «El mar profundo, que la nave temió surcar, hermoseado por las velas diseminadas por todas partes, como una alfombra, se ha hecho accesible para la juguetona barquilla y es posible contar los peces debajo del agua, cuando aquí hace muy poco las Cícladas, movidas bajo una ingente tempestad, tuvieron miedo del ponto". 
a la lucha. Caminaba lleno de ira dispuesto a vencer, cuando, enfrentados los suyos a los de Murro, fiel a los romanos, supo que, en la encarnizada lucha que mantenían, los dioses no parecían benévolos para su ejército. Silio muestra consternados a los dos ejércitos. En cuanto a Aníbal, su punta de lanza arroja luz, y el escudo parece lanzar rayos (iacit igneus hastae dirum lumen apex, ac late fulgurat umbo ${ }^{41}$, vv.1.466 ss.). Todos sentían un profundo miedo. $Y$ en este lugar, comenzando con talis, aparece el símil. (1. 468). Aníbal es como un huracán, que hace temer a los marineros que se encuentran en un mar que entra en la tierra, y a las mismas Cícladas.

talis ubi Aegaeo surgente ad sidera ponto perlongum vasto Cori cum murmure fluctus suspensum in terras portat mare, frigida nautis corda tremunt: sonat ille procul flatuque tumescens curvatis pavidas tramittit Cycladas undis ${ }^{42}$. (SIL. 1, 468-472).

Silio pone de relieve las tempestades del Egeo que sufren las Cícladas, y que ellas mismas, como los marineros, temen. La descripción de Silio es pormenorizada, el mar llegando a las estrellas (cf. surgente ad sidera), el oleaje que inunda la tierra (interris portat mare). El poeta ofrece el nombre del viento, el Coro, y casi escuchamos su bramido en el verso 469. Como antes en Ovidio (Tristia) se asombraban las Cícladas, aquí, también personificadas, tienen miedo (cf. tremunt y pavidas). No era difícil deducir cómo andaba Aníbal dispuesto a la lucha.

\section{ESTACIO}

11.1. Las Cícladas están asimismo en la obra épica de Estacio. En Aquileida encontramos a Tetis, madre de Aquiles, buscando un lugar donde esconder a su hijo. Ha contemplado las naves de los griegos dirigiéndose a Troya; sabe que su hijo no es inmortal; morirá, si participa en la guerra; por eso va a pedir al centauro Quirón que se lo entregue y, mientras está en la cueva del centauro, escuchando el canto de su hijo, piensa en qué lugar podría esconderlo ${ }^{43} \mathrm{y}$, tras rechazar algunos lugares posibles, piensa en enviarlo a la corte del rey Licomedes; entre las islas en las que hubiera podido ocultarlo están las Cícladas; de ellas, nombra a algunas. Así lo dice:

${ }^{41}$ «La ígnea punta de su lanza arroja una siniestra luz y su escudo lanza a lo lejos relámpagos».

${ }^{42}$ «Tal, cuando levantándose el ponto Egeo hasta los astros, el oleaje con el inmenso bramido del Coro lleva mucho tiempo a las tierras el mar que flota (encima de ellas), les tiemblan a los marineros sus helados corazones: suena aquel (sc. oleaje) lejos e, hinchándose por el viento, atraviesa las Cícladas llenas de pavor por las curvadas ondas».

${ }_{43}$ At Thetis undisonis per noctem in rupibus astans, / quae nato secreta velit, quibus abdere terris destinet, huc illuc divisa mente volutat. STAT. Ach. 1, 199s. 
De las Cícladas destaca el que no haya gran espacio entre las islas; están apretadas (artae); son muchas, como sabemos. De ahí, lógicamente, el peligro de navegar entre ellas. Las islas en las que piensa y después son despreciadas (spretae) son, pertenecientes a las Cícladas, Miconos, Sérifos (era pequeña, la llama humilis), y Delos, hospitalaria (hospita) para quienes, lógicamente, visitaban el templo de Apolo, o para los marineros en peligro, como ya hemos visto en otros textos. También menciona, y desprecia, la isla de Lemnos, de la que la diosa recuerda que las mujeres mataron a los hombres.

11.2. Y, de nuevo, en la Achilleida de Estacio aparecerán las Cícladas. Cuando Tetis se marcha de Esciros, dejando en la corte a Aquiles, al que como una hija recibe Licomedes, la diosa dirige unas palabras a la isla, para ella tierra querida. Como madre le ruega que guarde su secreto, como Creta guardó el de Rea (se entiende, ocultando a Zeus), y le anuncia, como diosa, que Esciros recibirá honores y superará en fama a la misma Delos. Al mencionar a Delos, Tetis destaca sus bondades, entre ellas, ser un lugar tranquilo y protector en las tormentas que se producen en las Cícladas. Dice así Estacio en relación a Delos:

te longus honos aeternaque cingent

templa nec instabili fama superabere Delo,

et ventis et sacra fretis interque vadosas

Cycladas, Aegaeae frangunt ubi saxa procellae,

Nereidum tranquilla domus iurandaque nautis insula ${ }^{45}$; (STAT. Ach. 1, 387-392).

Esciros, dice la diosa, será honrada en los templos que durarán por siempre y superará a Delos. Y, para dejar claro cuál será el futuro de Esciros, se detiene en la descripción de esta cíclada. Comienza aludiendo a su condición previa de isla errante, llamándola instabilis. Es sagrada (sacra) y, por eso, es respetada por los vientos y las aguas, frente a las demás cícladas, que soportan la agitación de las aguas que

${ }^{44}$ «A ella le agrada ir por las apretadas Cícladas. Son desdeñadas Miconos y la humilde Sérifos y Lemnos injusta con los hombres y Delos hospitalaria para las gentes».

${ }^{45}$ «A ti honor duradero y templos eternos te rodearán, y no serás superada en fama por la inestable Delos, sagrada para los vientos y para los estrechos y, entre las vadosas Cícladas, cuando las tempestades del Egeo rompen las rocas, morada tranquila de las Nereidas, e isla por la que han de jurar los marineros $(\ldots) »$. 
ocupan los espacios entre islas (cf. fretis); les atribuye, por tanto, un adjetivo que les conviene (cf. vadosas Cycladas). Delos, pues, cuando la violencia de la tempestad rompe los acantilados (saxa), en medio de las islas, está libre de peligro, es una tranquilla domus y protectora de los marineros. Como se colige, así será Esciros, según la promesa de Tetis, después de haber acogido a Aquiles.

11.3. Las Cícladas son mencionadas otra vez, cuando Calcante es obligado por los griegos a que utilice sus dones para «descubrir» dónde se encuentra el hijo de Tetis, ya que Aquiles es imprescindible para vencer a Troya. El adivino, que entra en éxtasis, dirá entre otras cosas (cf. vv. 1, 526-535) que ve a Tetis por las Cícladas buscando dónde esconder a su hijo, viendo también que Esciros, la tierra de Licomedes, será la isla elegida por la madre:

video per Cycladas altas

attonitam et turpi quaerentem litora furto.

occidimus: placuit Lycomedis conscia tellus ${ }^{46}$. (STAT. Ach. 1, 530-532).

En esta ocasión nada se dice de las Cícladas, salvo que Tetis está caminando por ellas. Calcante las ve «altas»; altas es la lectura de los manuscritos, pero se ha aceptado la conjetura de Shakleton Bailey que propone artas, 'apretadas', como se lee en el verso 204 de este mismo libro.

11.4. Y de nuevo aparecerán las Cícladas, cuando los griegos, informados por las palabras de Calcante, deciden marchar a Esciros y traerse de allí a Aquiles; Ulises, como se sabe, dirigía esa empresa. Aquiles vivía allí como una joven, pero su aspecto no impidió el amor entre él y una de las hijas de Licomedes; se llamaba Deidamía. Cuando los griegos llegan a Esciros, ya había nacido el hijo de la pareja. En cuanto al viaje de los griegos, Estacio describirá el itinerario, y en él están las Cícladas.

Iamque per Aegaeos ibat Laertia flexus puppis, et innumerae mutabant Cyclades oras; iam Paros Olearosque latent; iam raditur alta Lemnos et a tergo decrescit Bacchica Naxos, ante oculos crescente Samo; iam Delos opacat aequor: ibi e celsa libant carchesia puppi 680 responsique fidem et verum Calchanta precantur ${ }^{47}$. (STAT. Ach. 1, 675-680).

\footnotetext{
${ }^{46}$ «La veo (sc. a Tetis) atónita por las elevadas Cícladas y buscando el litoral para el torpe hurto. Estamos perdidos. Le ha agradado como cómplice la tierra de Licomedes».

${ }^{47}$ "Y ya la nave del hijo de Laertes iba por las sinuosidades del Egeo, y las innumerables Cícladas debilitaban los vientos. Ya se ocultan Paros y Oléaros; ya es rozada la alta Lemnos y, por la espalda, decrece Naxos, la de Baco, creciendo Samos ante los ojos; ya Delos da sombra al mar. Allí, desde lo alto de la popa ofrecen las cofas y ruegan que haya fidelidad de la respuesta y que Calcante sea verdadero».
} 
El poeta, al dar cuenta del camino de la nave de Ulises (Laertia puppis), habla de flexus, lógicamente, porque la nave no iba en línea recta, sino entre las islas; dejará claro que las Cícladas no son nueve, ni un número mayor, sino muchísimas, ya que no se pueden contar (innumerae), y se añade que cambiaban, en el sentido de 'aminorar', la fuerza del viento ${ }^{48}$. Menciona por su nombre las Cícladas ${ }^{49}$, Paros, Oléaros, Naxos y Delos. Nada dice de las dos primeras; a Naxos la llama bacchica; de Delos ofrece mayor información; es la isla de Apolo, al que se dirigirán los griegos, ofreciendo libaciones al dios y pidiéndole que ratifique las palabras de Calcante. En esta descripción no pasan desapercibidos detalles como los efectos ópticos, al acercarse o alejarse de la isla.

11.5. Estacio, el poeta que más veces ha nombrado a las Cícladas en su obra, volverá a darles presencia también en su Tebaida. En el libro tercero aparecen en un símil. El dios Marte, que recorre el mundo instigando a la guerra contra Tebas y que vuela acompañado de Furor, Ira, Pavor, etc. ${ }^{50}$, es muy semejante a Neptuno, cuando libera a los vientos de su prisión.

qualis ubi Aeolio dimissos carcere Ventos dux prae se Neptunus agit magnoque volentes incitat Aegaeo; tristis comitatus eunti circum lora fremunt Nimbique Hiemesque profundae

Nubilaque et vulso terrarum sordida fundo

Tempestas: dubiae motis radicibus obstant

Cyclades, ipsa tua Mycono Gyaroque revelli,

Dele, times magnique fidem testaris alumni ${ }^{51}$. (STAT. Theb. 3, 432-439).

Estacio ofrece el cortejo que acompaña a Neptuno, Nimbi, Hiemes, Nubila y Tempestas. No es favorable; las Cícladas, dubiae, no están firmes, sino que se han separado de sus raíces y son un obstáculo para ellas, y lo más asombroso es que la misma Delos, la Delos sagrada, respetada por vientos y aguas, no ha permanecido ajena.

${ }^{48}$ Mantengo en el verso 676 el texto de los manuscritos y coincido con la interpretación de Damsté (1908: 81). Estacio parece atribuir poéticamente a las Cícladas la virtud de mudar los vientos casi en brisas.

${ }^{49}$ Entre ellas menciona a Lemnos, que es una isla del Egeo, pero no una cíclada, y Samos, que pertenece al archipiélago de las Espóradas.

${ }^{50}$ Cf. STAT. Theb. 3, 424-431.

${ }^{51}$ «Es igual que cuando Neptuno a los vientos liberados de la cárcel de Eolo los empuja, como guía, delante de él y los lanza llenos de deseos contra el grande Egeo. Un siniestro cortejo para su marcha brama alrededor de sus riendas, Tormentas y violentas Tempestades y Nublados y la sórdida Tempestad en el fondo convulso de la tierra. Las Cícladas inseguras son un obstáculo para sus cimientos sacudidos y tú misma, Delos, temes ser arrancada de tu Micenas y tu Gíaros, e invocas la fidelidad de tu ilustre alumno». 
Por eso el poeta se dirige a ella (Dele), en segunda persona, consciente de que la isla, también personificada, tiene miedo (times) de que la arranquen de las islas Miconos y Gíaros con las que comparte cimiento; por eso, invoca (testaris) a Apolo, el dios que nació en ella y al que crió (cf. alumni). Estacio se ha detenido de modo singular en la isla de Delos.

11.6. En el libro quinto están dos veces las Cícladas, la primera, cuando Hipsípila narra la hazaña de las mujeres de Lemnos: asesinar a todos los hombres, maridos, hijos o hermanos. Es el momento en que aguardan la noche para matarlos y se acerca a Lemnos la expedición de Jasón, que se dirigía a la Cólquide en busca del vellocino de oro. Los ocupantes de la nave no vieron, sin embargo, la isla, porque a ella no llegaba la luz de los astros; sí eran visibles, en cambio, las Cícladas; de ellas se menciona una, Paros; también Tasos, no perteneciente a este archipiélago.

sera tamen mundo venerunt astra, sed illis

et Paros et nemorosa Thasos crebraeque relucent

Cyclades; una gravi penitus latet obruta caelo

Lemnos $^{52}$. (STAT. Theb. 5, 181-184).

En este caso solo se dice de las Cícladas que eran muchas, crebrae.

11.7. Las Cícladas aparecerán, por segunda vez en la Tebaida. Hipsípila es la única mujer que ha respetado la vida de un hombre, la de su padre; lo ha escondido, ha tenido que fingir que lo ha asesinado, y ahora tiene que confiarlo a una nave que lo lleve lejos de Lemnos. Pide ayuda a los dioses del mar, a los vientos y al Egeo:

qua data signa sequor; dein curvo robore clausum

dis pelagi Ventisque et Cycladas Aegaeoni

amplexo commendo patrem ${ }^{53}$. (STAT. Theb. 5, 287-289).

Estacio en esta ocasión ve las Cícladas abrazadas por el Egeo, y alude, sin duda,

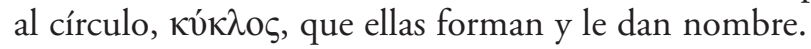

\section{JUVENAL}

Y acabamos nuestro recorrido por las Cícladas con un texto de Juvenal, en el que aparece por última vez el nombre de estas islas en la poesía latina. En la feroz crítica que el satírico lanza, sobre todo, contra las mujeres, pone de relieve el «vicio»

${ }^{52}$ "Tardíos, sin embargo, llegaron los astros al cielo, pero con ellos relucen Paros y la rica en bosques, Taso, y las abundantes Cícladas; una sola se oculta por completo bajo el pesado cielo, Lemnos».

${ }^{53}$ "Yo sigo las señales recibidas. A mi padre, al que encierro en el curvo roble, lo encomiendo a los dioses del piélago, a los Vientos y al Egeo que abraza las Cícladas». 
que tenían de consultar para todo a los adivinos; los había de toda clase y condición, ponderando en estos versos que eran los más valorados y fiables los que habían sufrido algún castigo, afirmación que ilustra con haber llevado cadenas o haber estado preso. A modo de cierre de lo que ya había referido, sentencia con autoridad que, sin haber sido castigado, no hay astrólogo que valga (nemo mathematicus genium indemnatus habebit), aunque, sin embargo, apostilla, con un sedy, como retractándose, que sí podían tener credibilidad (cf. genium habere) los que habían escapado de la muerte o habían tenido la suerte de librarse de ser relegados a una Cíclada, cuando estuvieron a punto de ser enviados a ella. Así lo leemos en la sátira sexta de Juvenal:

Inde fides artis, sonuit si dextera ferro

Laevaque, si longe castrorum in carcere mansit;

nemo mathematicus genium indemnatus habebit,

sed qui paene perit, cui vix in Cyclada mitti

contigit et parva tandem caruisse Seripho ${ }^{54}$. (Ivv. 6, 560-564).

Juvenal primero (v. 563) se refiere con el acusativo griego a una isla del archipiélago, de la que, al final del hexámetro siguiente, dará el nombre: Sérifos. Es, como se sabe, una pequeña isla de las Cícladas, aunque se le dice salutifera, no demasiado importante; de ella se sirvieron los romanos para enviar allí a quienes habían cometido delitos castigables con la relegación ${ }^{55}$.

13. Hasta aquí las Cícladas y los textos en los que aparecen. Quería escribir sobre las islas, y Clementson y su Archipiélagos me hicieron dirigir la mirada al de las Cícladas, y me condujeron a este recorrido por la poesía latina. A él lo movió entre otros Lord Byron, del que tradujo, con la maestría que se le reconoce, unos preciosos y profundos versos ${ }^{56}$. No necesitan glosa:

¡Las islas de Grecia, las islas de Grecia,

Donde amara y cantara la apasionada Safo

Y crecieron las artes de la paz y la guerra,

Donde Delos se alzó y surgió Febo!

Aún las dora un eterno verano,

Mas todo, salvo su sol, ya se ha eclipsado.

${ }^{54}$ «De ahí el crédito de su arte, de si la derecha y la izquierda sonó con el hierro, de si ha permanecido largo tiempo en la cárcel militar. Ningún astrólogo no condenado tendrá talento, pero sí el que casi perece, o aquel al que le tocó ser enviado a la cíclada apenas cuando (le tocó) ser librado de la pequeña Sérifos».

${ }_{55}^{5}$ Tácito ofrece dos ejemplos en Anales, el de Vestilia (Ann. 2, 85), y el de Casio Severo (4, 21).

${ }^{56}$ Aparecen en su Archipielagos junto a textos de Sófocles, Friedrich Hölderlin, Yannis Ritsos y Yorgos Seferis, precediendo al Poemario. Aquí se sitúa como cierre de estas páginas. 


\section{A MODO DE CONCLUSIÓN}

El recorrido por estos preciosos textos de la poesía latina nos ha corroborado que la presencia en ellos depende, en su mayor parte, de la posición geográfica en que se encuentran las Cícladas. Por ellas, sea cruzándolas o rodeándolas tienen que pasar quienes viajan por el mar Egeo, sean divinidades, como Tetis o Ceres, o imágenes como la de Cibeles, héroes, como Eneas o Jasón, o seres humanos como Catulo u Ovidio. Encontrar el nombre de las Cícladas en la poesía latina nos ha aportado alguna información, que podría considerarse como conclusiones. También las islas que se encuentran en los textos junto a las Cícladas aportan noticias. Así:

El número de islas no es nueve, como Higino decía, sino que su número es, como se sabe, mucho mayor; lo confirman nuestros textos que aplican a Cícladas los adjetivos innumerae (STAT. Ach. 1, 676) o crebrae (StAT. Theb. 5, 183). Parecen sembradas o esparcidas por la llanura del mar Egeo, como confirma el participio sparsae (VerG. Aen. 3, 126). El número elevado de ellas explica que se las diga artae (STAT. Ach. 1, 204) y motiva que no haya gran espacio de mar entre las islas; estos espacios los llaman freta (Verg. Aen. 3, 127) o se refieren a ellos con aequora interfusa (Hor. Carm. 1,14 19-20, y ellas son vadosae (STAT. Ach. 1, 1, 389s.). No se olvidan los poetas de indicar su situación en el mar: Aegeae (Ov. Trist. 11, 8), o abrazadas por el Egeo (STAT. Theb. 5, 288). Y tampoco Manilio omite que son diferentes unas de otras: inaequales (MANIL. 4, 637). Algunas de ellas abundan en mármoles, que brillan, especialmente, con los rayos del sol; de ahí los poetas las califican como nitentes (HoR. Carm. 1, 14, 19-20), fulgentes (Hor. Carm. 3, 8, 29), florentes (CirIs 471). También altae (STAT. Ach. 1, 530). Nada se dice de ellas en Ov. Fast. 4, 281 y 565.

Pero también el nombre de las Cícladas va unido a las tempestades del Egeo y los poetas se sirven de ello. A las Cícladas convienen adjetivos como revolsae (VERG. Aen. 8, 691), motae (SEn. Thy. 595), dubiae (STAT. Theb. 3, 438), pavidae (Sil. 1, 471), y les atribuyen acciones como hablar: negare (CATVLL. 4, 7), asombrase: obstipuisse (Ov. Trist. 11, 8), tener miedo: timuere (SEN. Thy. 595).

En cuanto a las islas, se puede saber de Citno que está rodeada de espuma (Ciris 475), de Donusa, que es viridis (Verg. Aen. 3, 125 y Ciris 476); que a Naxos conviene el adjetivo bacchata (VerG. Aen. 3, 125) y bacchica (STAT. Ach. 1, 678), a Paros el de nivea (VERG. Aen. 3, 126) y marmorea (CIRIS 476); y a Sérifos los de salutifera (Ciris 477), humilis (STAT. Ach. 1, 205) y parva (Ivv. 6, 564).

Dejamos al final Delos. Está en el centro de las Cícladas, y los textos confirman que ella está por encima de todas las islas. Ella es gratissima Nereidum matri et Neptuno (CiRIS 473 ss.), hospita gentibus (STAT. Ach. 1, 206s.), ventis et sacra fretis (STAT. Ach. 1, 389), Nereidum tranquilla domus, y iuranda nautis (STAT. Ach. 1, 391); Apolo es su magnus alumnus (STAT. Theb. 3, 439); es alta (STAT. Ach. 1, 530). Su historia la canta un bello coro de Séneca (SEN. Ag. 384-391). Es mencionada sin decir nada de ella (MANIL. 4, 637 y STAT. Ach. 1, 679).

Son bastantes las islas pertenecientes al archipiélago de las Cícladas que los textos ofrecen; a las mencionadas se pueden añadir otras citadas, pero de las que nada se dice. Así: Egina (Ciris 477), Gíaros (Stat. Theb. 3, 438), Miconos (Stat. Ach. 1, 205 y STAT. Theb. 3, 438), Oléaros (Verg. Aen. 3, 126, y Stat. Ach. 1, 677), Ortigia (Verg. Aen. 3, 124) y Paros (Stat. Ach. 1, 677). 
Estas islas han sufrido tormentas, y esta realidad ha propiciado estar en la poesía como símil; es la función más literaria de las Cícladas; la encontramos cuando el poeta acude a ellas para evidenciar grandes peligros. Virgilio fue el primero (VERG. Aen. 8, 691), las Cícladas parecían nadar, arrancadas de sus cimientos (cf. revolsas, innare); el ejemplo de Virgilio lo siguieron Senéca (SEN. Thy. 590-595), con un solo verso, el 595 (Cyclades pontum timuere motae) o Silio (SIL. 1, 468-471), en los vv. 471 ss. (fluctus (...) flatuque tumescens/ curvatis pavidas tramittit Cycladas undis).

La presencia de las Cícladas en los textos, en concreto, el modo de referirse a algunas de sus islas ilumina las relaciones de dependencia que ya conocíamos; valga de ejemplo la coincidencia de Virgilio y Ciris en el adjetivo viridis para Donusa, o la cercanía de bacchata y bacchica de Virgilio y Estacio, respectivamente, para Naxos.

Las Cícladas están en toda clase de textos En la poesía latina las hemos encontrado en bellísimos pasajes de la épica (Virgilio, Ovidio, Silio, Estacio, en un epilio: Ciris), en la lírica y elegíaca (Catulo, Horacio, Ovidio, en los coros de la tragedias de Séneca), en la poesía didáctica (Manilio) y en la sátira (Juvenal). Unas u otras razones las llevaron a ellos. Lo habitual es que el poeta las introduzca a propósito de un viaje; en otros casos porque describe el mundo, y en el mundo están (Manilio), o porque viajan para quedarse en ellas, y no por voluntad propia, quienes han merecido la relegación (como vemos en Juvenal).

Las Cícladas han sido testigos de la vida de muchos seres, conocidos o sin nombre, mitológicos e históricos. Millones de seres humanos han vivido en ellas, las han visitado, han pasado por ellas. Ellas tienen su historia y han contribuido al nacimiento y desarrollo de nuestra civilización. A nosotros el nombre nos sirve para felicitar a Fortunatae, y desear que La Palma sea muy pronto la isla fortunata que ha sido siempre. Siempre lo seguirá siendo.

\section{REFERENCIAS BIBLIOGRÁFICAS}

De La Cerda, J. L. (1612): Virgilii Maroni Priores sex libri Aeneidos, argumentis, explicationibus, notis illustrati, auctore Ioanne Ludovico DE LA CERDA, Lugduni, sumptibus Horatii Cardon.

Clementson, C. (1995): Archipiélagos (La Sinfonía Helénica), Universidad Popular, San Sebastián de los Reyes.

Damsté, P. H. (1908): «De verbi mutandi usu apud P. Papinium Statium», en Sertum Nabericum collectum a philologis batavis ad celebrandum diem festum XVIum mensis Iulii anni MCMVIII, E J. Brill, Leiden, pp. 77-84.

Moya del Baño, F. (1982): «Virgilio y la Appendix Vergiliana», Helmantica 33 (101-102): 407-448.

Pérez Vega, A. - Ramírez de Verger, A. (2005): C.Valerii Catulli Carmina. Catulo Poemas, edición, traducción y comentario de A. Pérez Vega - A. Ramírez de Verger, Fundación del Monte, Huelva.

Ruiz de Elvira, A. (1975): Mitología Clásica, Gredos, Madrid.

Servivs (1961): Servii Grammatici qui feruntur in Vergilii Carmina Commentarii, vol. I, Georg Olms, Hildesheim. 
